
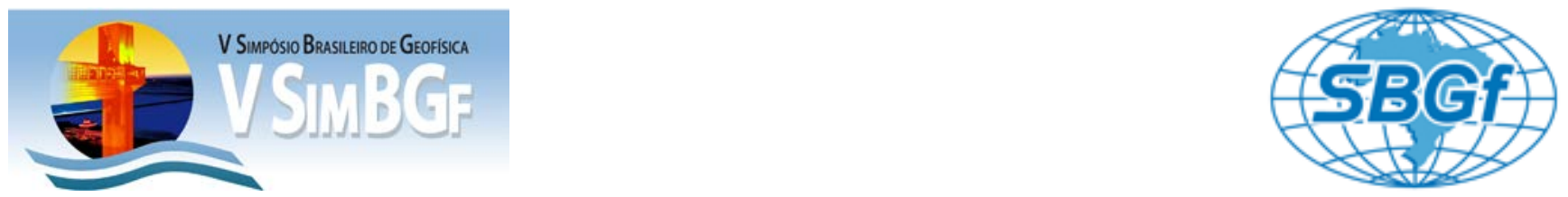

\title{
Reativação da Falha de Samambaia em 2011
}

Joaquim Mendes Ferreira ${ }^{1,2}$, Renato Ramos da Silva Dantas ${ }^{3}$, Heleno Lima Neto ${ }^{2}$, Aderson Farias do Nascimento ${ }^{1,2}$, Eduardo Alexandre de Menezes ${ }^{1}$, Regina Spinelli ${ }^{1}$, Neymar Pereira da Costa ${ }^{1}$

${ }^{1}$ Departamento de Geofísica/UFRN

${ }^{2}$ Programa de Pós-graduação em Geodinâmica e Geofísica/UFRN

${ }^{3}$ Curso de Graduação em Geofísica/UFRN

Copyright 2012, SBGf - Sociedade Brasileira de Geofísica

Este texto foi preparado para a apresentação no V Simpósio Brasileiro de Geofísica, Salvador, 27 a 29 de novembro de 2012. Seu conteúdo foi revisado pelo Comitê Técnico do V SimBGf, mas não necessariamente representa a opinião da SBGf ou de seus associados. É proibida a reprodução total ou parcial deste material para propósitos comerciais sem prévia autorização da SBGf.

\section{Resumo}

Depois de muitos anos sem tremores sentidos pela população a Falha de Samambaia, na região de João Câmara-RN voltou à atividade. Desde o início de 2011 foram registrados eventos tanto pela estação analógica de Lagoa do Serrote (TPLS) quanto pela estação de Riachuelo (RCBR).

Essa atividade recrudesceu em outubro de 2011 quando alguns eventos seguidos foram sentidos pela população. Após isso, uma rede sismográfica foi instalada na região para determinar, com precisão os hipocentros dos sismos.

O presente trabalho analisa os dados registrados pelas diversas estações em 2011 e início de 2012. O principal resultado obtido foi mostrar que, embora a Falha de Samambaia tenha cerca de $40 \mathrm{~km}$ de extensão os sismos só ocorreram em três pontos da mesma.

\section{Introdução}

A Falha de Samambaia é a principal falha ativa do país, com cerca de $40 \mathrm{~km}$ de extensão. O máximo de atividade ocorreu entre 1986 e 1997 quando foram registrados mais de 50.000 eventos, 2 deles de magnitude maior ou igual a 5.0 e mais de 20 de magnitude maior ou igual a 4.0, o que causou sérios danos materiais e pânico e fuga da população. Uma visualização da localização dos eventos de maior magnitude pode ser feita na Figura 1. Após um longo período sem atividade aparente, embora o monitoramento próximo não tenha sido feito continuadamente desde o final dos anos 90 , no começo de 2011 alguns eventos voltaram a ser registrados pela estação TPLS. Como foi dito anteriormente, em outubro ocorreu um surto de atividade com vários sismos sentidos pela população.

Antes da implementação da rede sismográfica, em outubro de 2011, a localização dos epicentros, quando possível, era feita a partir dos registros da estação de RCBR, ao sul da Falha de Samambaia (Figura 1). Esse método, embora com algumas limitações na determinação azimutal é suficiente, sem maiores problemas, para saber em que região da Falha de Samambaia está ocorrendo a atividade sísmica.

Outro parâmetro que se tentou identificar foi a da distribuição da magnitude, obtida na estação TPLS, com o tempo. Os resultados obtidos serão discutidos adiante.

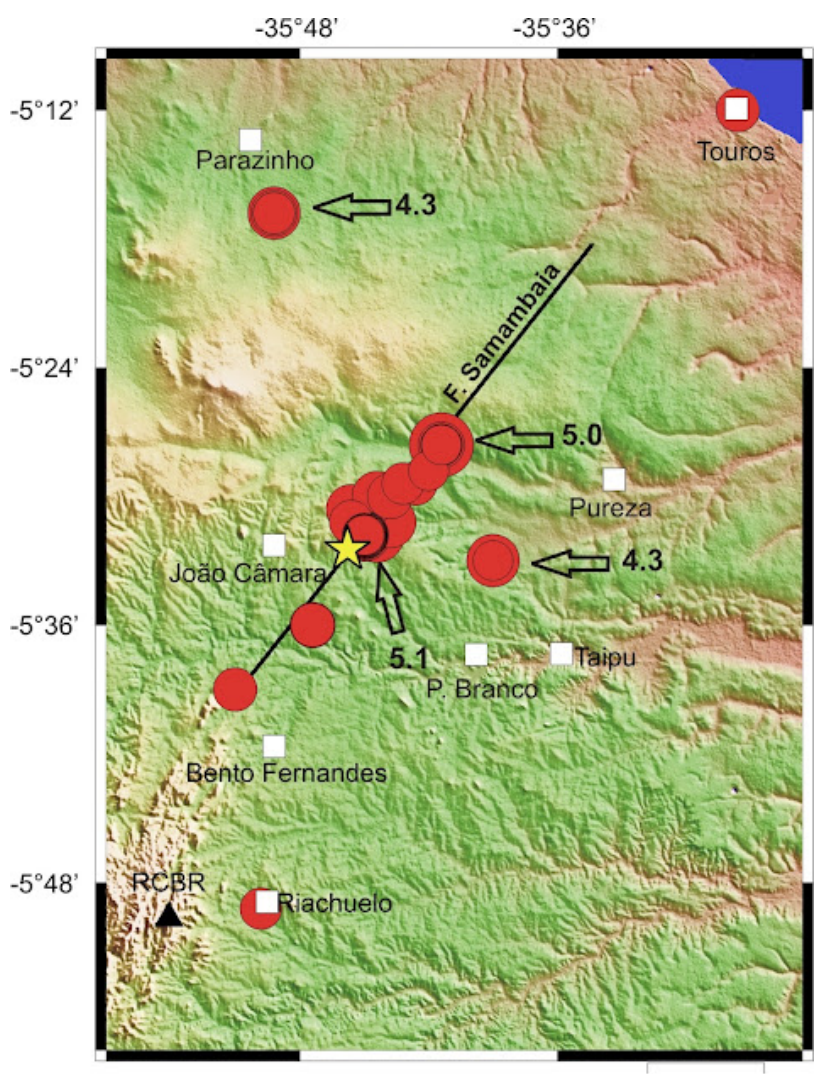

$10 \mathrm{~km}$

Figura 1. Sismos de magnitude maior ou igual a 3.5 na região de João Câmara, dados históricos (Touros e Riachuelo) e instrumentais. São indicadas as magnitudes e epicentros dos dois maiores tremores da Falha de Samambaia bem como de outros eventos de magnitude acima de 4.0 ocorridos na região. A estrela amarela indica o epicentro do sismo de outubro de 2011.

\section{Metodologia}

A determinação epicentral a partir da estação RCBR foi feita utilizando o programa Dimas que dá a leitura das fases $P$ e $S$, necessárias para a determinação da distância epicentral, e o azimute da chegada da onda sísmica à estação.

A determinação da magnitude na estação TPLS, analógica, foi feita através da medida da duração do sinal em seu registro, utilizando a fórmula de Blum e Assumpção (1990).

Para a determinação dos epicentros da rede sismográfica local foi usado o programa HYPO71. 


\section{Resultados}

A determinação epicentral mostrou que a atividade sísmica em 2011 e começo de 2012 ficou restrita a três áreas relacionadas à Falha de Samambaia, conforme mostra a Figura 2.

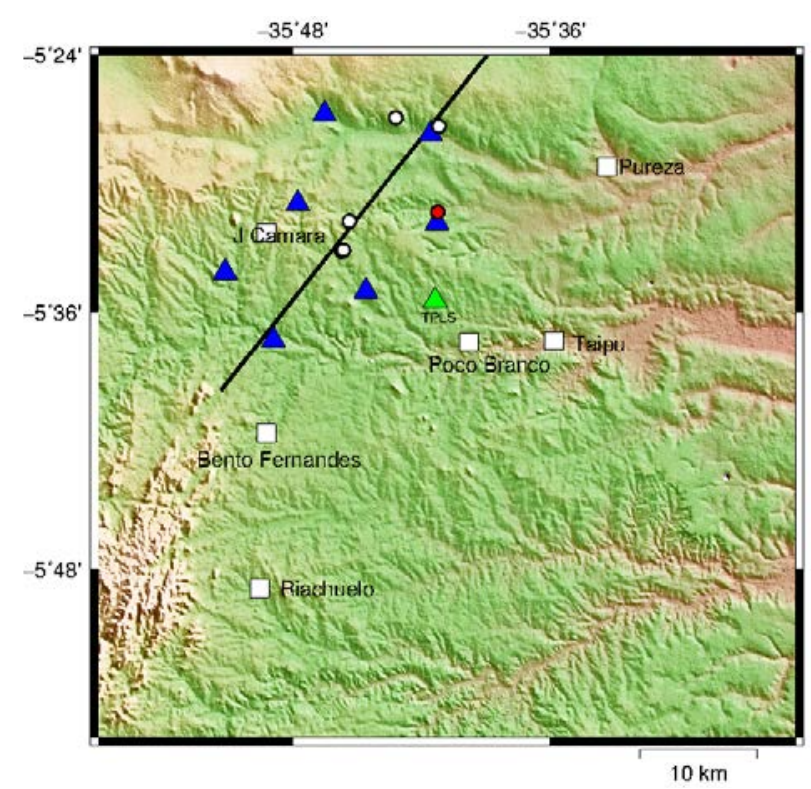

Figura 2. Epicentros do sismo de 12/03/2011 (em vermelho) e de sismos registrados pela rede sismográfica (círculos brancos). Os triângulos azuis mostram as estações da rede. Também é mostrada a localização da estação TPLS (triângulo verde).

Dessa forma, pudemos comprovar que a atividade sísmica iniciou-se, em 2011, na região de SamambaiaLagoa Rachada (círculo vermelho, Figura 2). Em outubro do mesmo ano a atividade sísmica migrou para a região do Matão (círculos brancos ao sul), onde, em 1986 ocorreu um tremor de magnitude 5.1. No início de dezembro de 2011 a atividade migrou para o norte coincidentemente onde ocorreu um tremor de magnitude 5.0 em 1989.

Em outubro de 2011 visualmente foi possível identificar que a relação entre sismos de maior e menor magnitude provavelmente não obedecia a lei de Gutenberg-Richter para a distribuição do número de sismos com a magnitude.

Em vista disso, foram calculadas as magnitudes de todos os eventos desde o início de 2011 até o início de 2012. Verificou-se então que, para os sismos ocorridos antes de outubro (na região de Samambaia-Lagoa Rachada) é válida a lei de Gutenberg-Richter (Figura 3) pois todos estão próximos a uma reta em $(\mathrm{M}, \log (\mathrm{N}))$, onde $\mathrm{N}$ é o número cumulativo de sismos de magnitude $\geq \mathrm{M}$.

Para os eventos a partir de outubro de 2011, que ocorreram ou próximos do epicentro de magnitude $5.1 \mathrm{ou}$ próximos ao epicentro de magnitude 5.0 a distribuição dos sismos não está sobre uma só reta (Figura 4).

Resumindo, sismos fora das regiões onde ocorreram os maiores eventos obedecem à lei de Gutenberg-Richter mas os eventos relacionados com as áreas onde ocorreram os eventos de magnitude 5.1 e 5.0 não obedecem a essa lei.

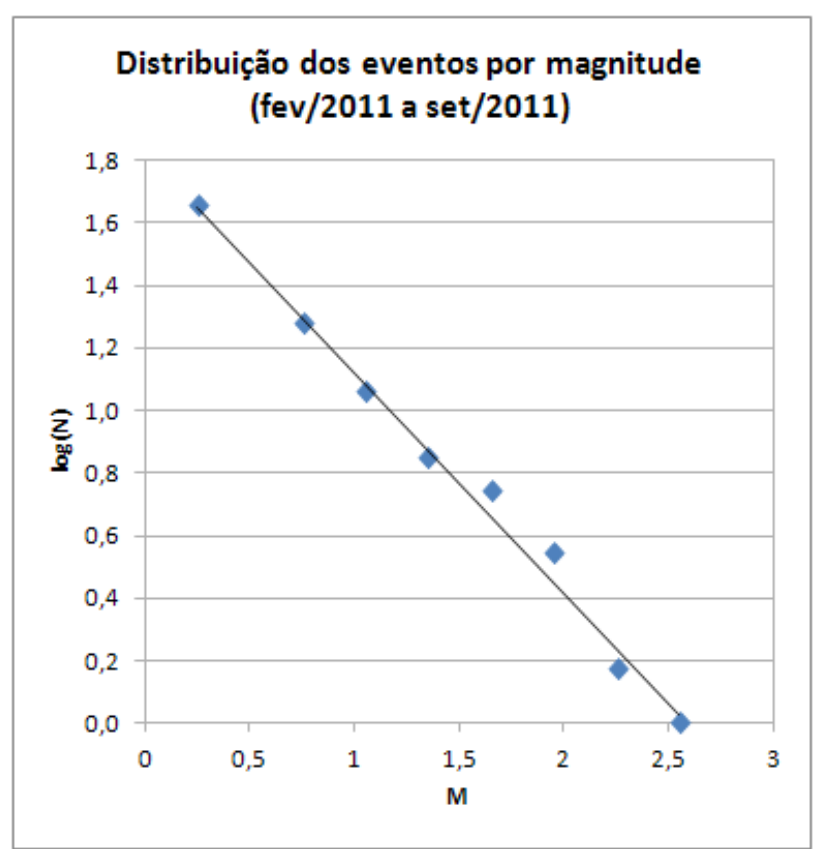

Figura 3. Distribuição dos eventos por magnitude entre fevereiro e setembro de 2011.

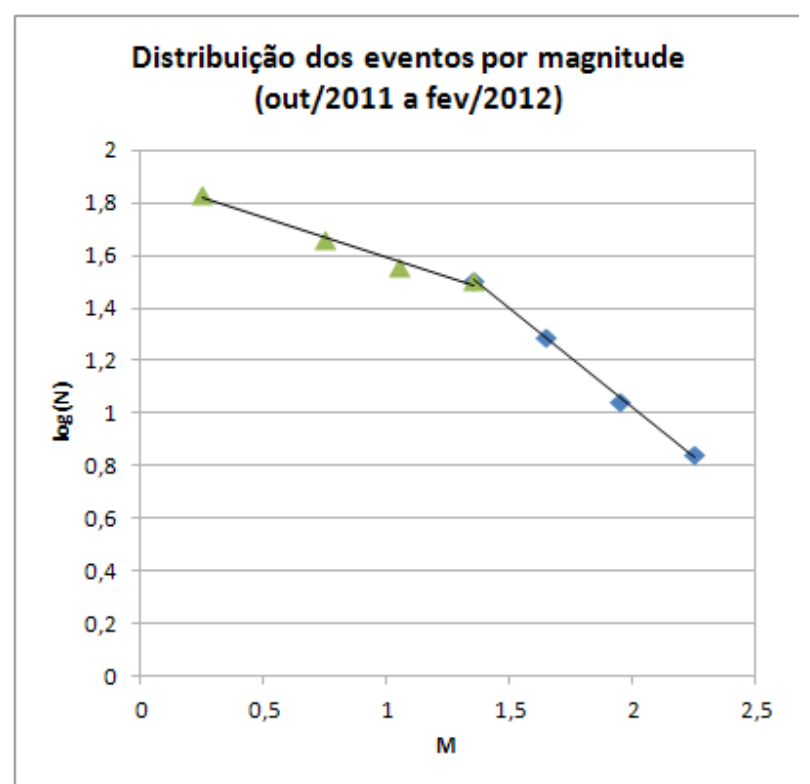

Figura 4. Distribuição dos eventos por magnitude entre outubro/2011 e fevereiro/2012. 


\section{Discussão e Conclusões}

O resultado mais importante obtido está relacionado com a lei de Gutenberg-Richter. Na prática, o que foi mostrado é que, a partir de outubro de 2011 a razão entre sismos de maior e menor magnitude é maior que o normal (lei de G-R). As causas para esse efeito podem estar relacionadas com a reologia das regiões onde ocorreram os maiores tremores ou seja, na prática, o movimento da falha é aí mais difícil só ocorrendo aos solavancos.

\section{Agradecimentos}

O trabalho de campo foi financiado pelo INCT de Estudos Tectônicos. JMF e AFN agradecem ao CNPq pela bolsa de $\mathrm{PQ}$. RRSD agradece à ANP pela bolsa do $\mathrm{PRH} 22$.

\section{Referências}

Bezerra, F.H.R. et al. (03 co-authors), 2007. Coseismic reactivation of the Samambaia fault, Brazil. Tectonophysics, 430: 27-39.

Blum, M.L. \& Assumpção, M., 1990. Estimativa do parâmetro b dos sismos de Palhano, Ceará, de outubro de 1988. XXXVI Congr. SBG, Natal, RN, Anais 5:21602163.

Ferreira, J.M. et al. (06 co-authors), 1987. A continuing intraplate earthquake sequence near João Câmara, northeastern Brazil - preliminary results. Geophys. Res. Lett., 14:1042-1045. 